\title{
The Cyclical Movement of Steel Scrap Prices
}

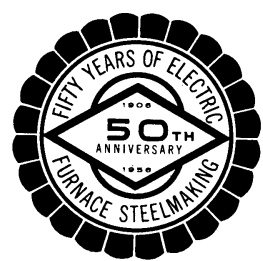

Based on an Article

by Chapin Hoskins

\author{
Since 1948, a continuous study of the price of scrap steel \\ has been carried on at the Institute for Trend Research \\ (ITR) under the sponsorship of Lukens Steel Co. \\ The present informal report on cycles in the price of steel \\ scrap shows what can be learned when fluctuations in price \\ are studied somewhat as the background of an engineering \\ problem is studied.
}

$I^{\mathrm{N}}$ the ITR studies of steel scrap behavior, American Metal Market monthly and Iron Age weekly prices from 1901 to the present time have been used. Statements in this report are based on monthly prices of Number One Heavy Melting at Pittsburgh.

In the first quarter of the present century, Pittsburgh Number One Heavy Melting once sold at around $\$ 10$ a ton and once at nearly $\$ 41$; in the second quarter century, its extremes were $\$ 8$ and $\$ 46$; during 1956 it has reached $\$ 58$. Thus, we can begin with a statement that the price of scrap rises and falls over periods of time and then proceed to the very simplest definition of a cycle in scrap price, namely: a cycle is a rise followed by a decline. More precisely stated, a scrap price cycle is a wave in which monetary value is a vertical dimension and time is the horizontal dimension. For convenience the cycle can be measured from low point to low point, although other points of measure are possible.

The structure of waves in steel scrap price is such that waves of one approximate dimension are most obvious, but these are really riding on the backs of still larger waves, and their own surfaces are ruffled by smaller waves.

Minor Waves: Among the rippling waves in scrap price, one type is seasonal in nature; in general, this is a semiannual movement. Usually it can be observed only at times when the force of larger cyclical movement is slight. But there are also other minor waves of a nonseasonal nature.

Major Waves: The greatest discernible wave in scrap price is delineated by a decline of 54 pct between 1902 and 1914, a rise of 303 pct from then to 1917 , a decline of 80 pct into 1932 , and a rise of 604 pct since then. This wave is clearly associated with the coming and going of war and peace.

\section{The Operating Cycle}

In between the major waves and the minor waves in both horizontal and vertical dimensions is a class of wave in scrap price which we can conveniently call The Operating Cycle. A wave of this character tends to last approximately two, three, or four years, but in time of war, it may last longer than four years.

A simple characteristic of this cycle is that at its beginning, the price of scrap has always been lower than it was a year earlier; at its crest the price is

CHAPIN HOSKINS is Chairman of the Trustees of the Institute for Trend Research, Hopkinton, N. H. This paper is to be presented at the Electric Furnace Steel Conference, Chicago, December 1956. higher than a year earlier; and at its end the price is again lower than a year before the end.

Between 1900 and 1954 there were 17 such cycles. In the majority of these the price rose 45 pct or more in one year; in a third of them more than 65 pct. In the declining phases of the 17 cycles, the price has, in a majority of cases, fallen 31 pct or more in one year; see Fig. 1.

Clearly, the extent of these rises and declines and their importance to users and providers of scrap make this a cycle of great importance to those with operating or executive responsibilities. This is why it has been dubbed The Operating Cycle.

Measuring and Observing the Cycle: An effective way to measure cyclical price change is to compute a continuous record of its rate of change. This means dividing the amount of change-the vertical wave component-by a unit of time-the horizontal wave component. Thus, it is possible to calculate change per year, per decade, per month, per week, or per any other chosen span of time.

Rate of change per 12 months is a particularly useful measure for the identification of cycles of two to four years. One reason is that this measure nullifies the effect of price changes that may be purely seasonal.

Engineers will recognize this simple calculation as a first derivative. In constructing a 12-month rate of change series for Pittsburgh scrap, the price at January, 1902 was divided by the price at January, 1901, the February, 1902 price by the February, 1901 price, and so on. The resulting percentage in each case is, in our language, a 1/.12 pressure.

In Fig. 2 is shown a sample operating cycle, with the actual price variation in the top portion and the cycle in terms of $1 / 12$ pressure at the bottom.

During its progress, the rate of change cycle, shown in Fig. 2, passed through four phases:

\begin{tabular}{|c|c|c|c|}
\hline Phase & Position of Price & Rate of Change & $\begin{array}{l}\text { Length } \\
\text { in } \\
\text { Months }\end{array}$ \\
\hline \multirow[t]{2}{*}{$\begin{array}{l}\mathrm{A} \\
\mathbf{B} \\
\mathbf{C} \\
\mathrm{D}\end{array}$} & $\begin{array}{l}\text { Below previous year } \\
\text { Above previous year } \\
\text { Above previous year } \\
\text { Below previous year }\end{array}$ & $\begin{array}{l}\text { Rising } \\
\text { Rising } \\
\text { Declining } \\
\text { Declining }\end{array}$ & $\begin{array}{r}9 \\
3 \\
16 \\
7\end{array}$ \\
\hline & & Total & 35 \\
\hline
\end{tabular}

This can be considered a specimen cycle, but, although no two cycles are exactly alike, these general statements can be made: 


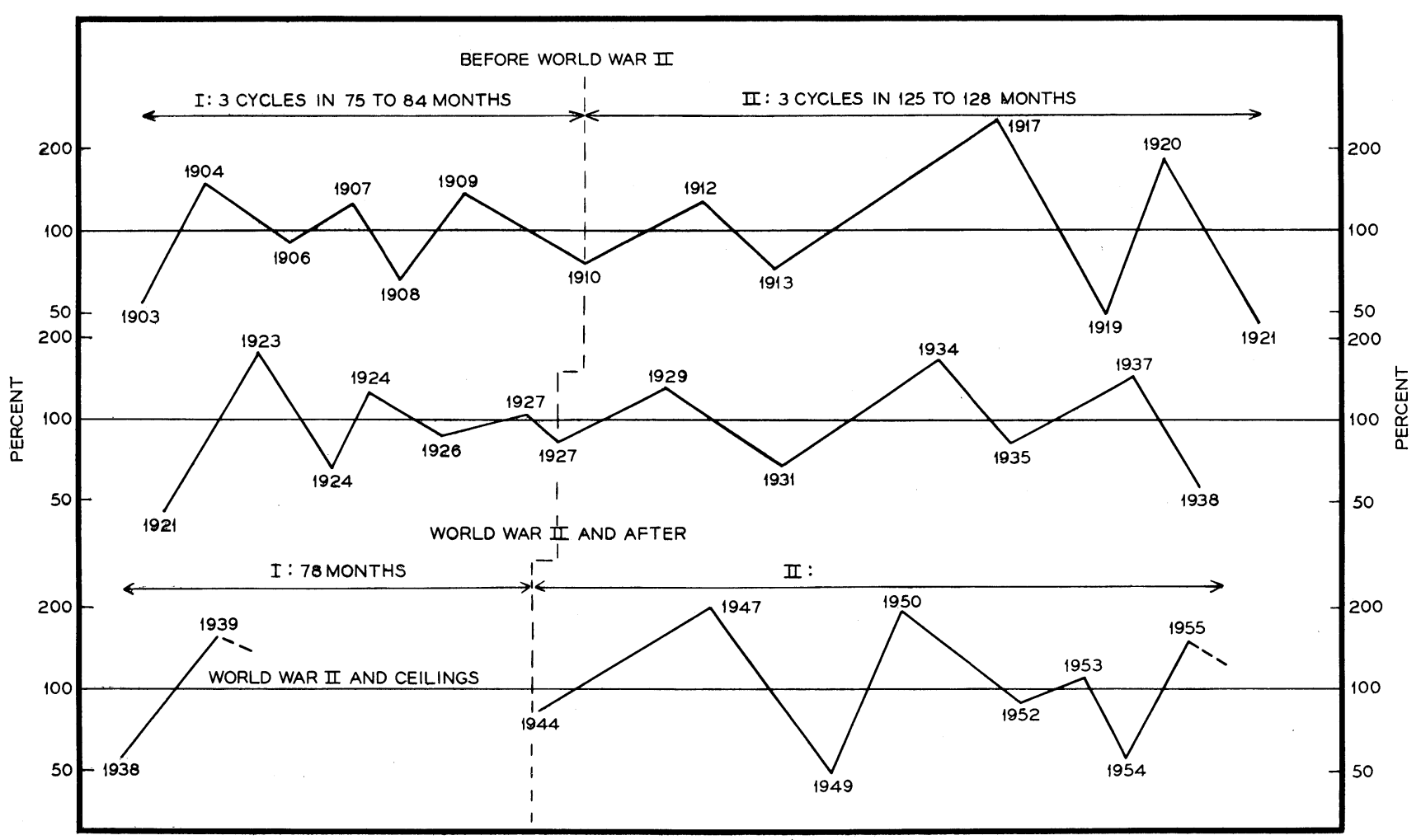

Fig. 1-Between 1900 and 1954 there were 17 Operating Cycles, each lasting from 2 to 4 years. Shown is a 12-month rate of change series for Number One Heavy Melting scrap at Pittsburgh.

1) For more than 50 years, except during the period of wartime price ceilings, scrap price has. experienced a succession of such cycles;

2) All 17 recorded cycles have passed through all of the ABCD phases;

3) In peacetime, no cycle has been more than 46 months long. This means that no period of four years has gone by without scrap passing at least once through all four ABCD phases; and

4) No cycle has lasted less than 20 months (virtually two years).

\section{Dynamics of Cyclical Change}

In all 17 of the scrap cycles, Phase $A$ has been followed by Phase B. This seems to mean that, once the rate of change has begun to rise, after a Phase $D$, forces have been set in motion which will, within a number of months, drive the price higher than it was a year earlier. Phase B has always been followed by Phase C, and Phase C by Phase D.

Dynamic Details: From its beginning to its end, each cycle in scrap price appears to be subject to dynamic laws just as definite as a wave motion in a physical body.

The length of Phase A depends greatly on how long the rate of change has remained in Phase D. The relation is so close that, if in 16 cases the length of Phase $\mathrm{D}$ is taken and a constant of 3 months subtracted, then in nine cases a median error of 1 month and a maximum error of 2 months is made in calculating the length of Phase A.

Furthermore, the amplitude-depth-of Phase D appears to influence the amplitude-height - of Phase B. Therefore, Phase D has an important bearing on what happens during the next 12 months or more, because the crest of Phase B is rarely reached in less than 12 months after the end of Phase D.

Actually, the influence of Phase D extends farther than 12 months. Out of the 17 recorded cases: in the four cycles which had the highest amplitude, the median-average length of Phase $C$ was $11 \frac{1}{2}$ months; in the four cycles rising next highest, the median-average length of $\mathrm{C}$ was $81 / 2$ months; the cycles which ranked 10 to 13 in amplitude had Phase C's with a median-average of $7 \frac{1}{2}$ months; and in the four cycles of least amplitude, the medianaverage of Phase $\mathrm{C}$ was only $11 / 2$ months. Conformity is sufficient to justify a general statement of tendency: The higher the pressure rise in Phase $B$, the greater the length of Phase $\mathrm{C}$.

Thus, it will be seen that the influence of Phase D extends at least to the end of the next Phase C. This, it will be remembered, is the point at which the price again falls below that of a year earlier. And, since in the majority of cycles the end of Phase $C$ has occurred more than two years after the beginning of the cycle, it will be seen that conditions at the start of the cycle are likely to show their mark for at least that length of time.

These examples of scrap steel price dynamics suggest the existence of what might be considered potential energy at the bottom and the top of each cycle. Actually, the situation at every step in the cycle appears to have a bearing on the timing and amplitude of future change.

But what about economic conditions, the supply of and demand for scrap, and so on? Surely these are the primary factors in the rise and fall of scrap prices.

Two statements are suggested for consideration:

1) The influences of supply and demand normally operate within limits set by price dynamics. These influences tend to modify dynamic trends, but only under very unusual conditions can they completely alter them; and

2) The supply situation and the demand situation at any given time are themselves largely the results of dynamic situations and previous dynamic change. 


\section{Are Scrap Cycles Periodic?}

There is considerable evidence that the rate of change cycles in steel scrap price tend to be periodic. The periodicity is not simple but compounded of periods of different length. This can be clearly observed on an ITR Time Chart, ${ }^{1}$ but can be only broadly described here.

Two of the most serious $1 / 12$ pressure declines in scrap price ended in December, 1903 and in April, 1938. These points of time were 412 months apart.

Two of the most violent rises ended in December, 1904 and October, 1939. These were 418 months apart.

Two other violent pressure rises ended in October, 19.12 and August, 1947. These were also 418 months apart.

The low following the Armistice of World War I was 420 months before the low following the Korean Armistice.

All of these intervals, it will be seen, are not far from 416 months, and very nearly all of the 136 simple and compound intervals between the. beginnings and ends of 16 cycles could be harmonically related to an interval of approximately 416 months. Traces of other periodic tendencies appear in the time charts, but the 416 months harmonic tendency seems by far the most important.

The interesting way in which these harmonics appear to combine can be simply illustrated by a synopsis of what has happened in each $171 / 3$ years of the record (17 1/3 years, 208 months, or half of 416 months).

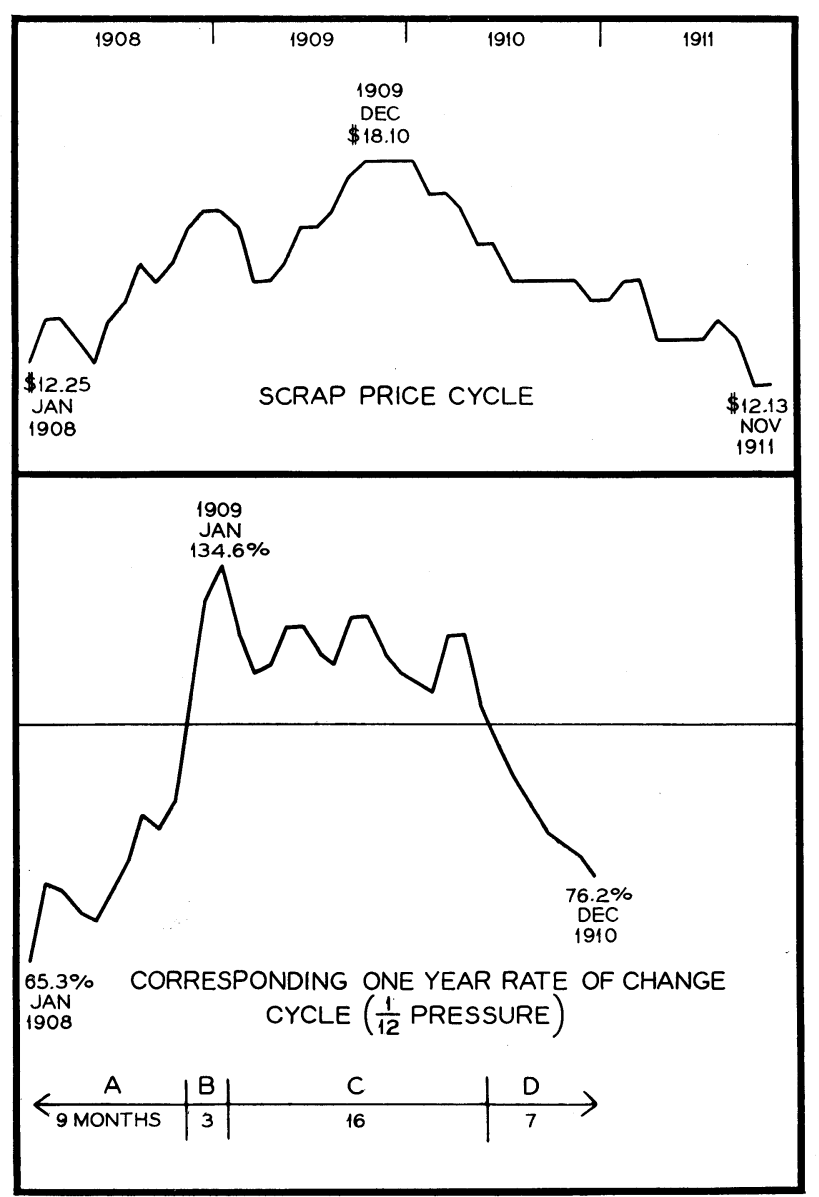

Fig. 2-A sample Operating Cycle, with actual price variation shown above and the cycle in terms of $1 / 12$ pressure below.
The first complete $1 / 12$ cycle began in December 1903. In December 1910, 84 months later, three cycles had been completed, with an average length of 28 months. In the next 128 months, to August 1921, three more cycles had been completed, this time with an average length of $422 / 3$ months. The total period of these six cycles was 212 months.

After August 1921 three cycles occurred in 75 months. The end of these cycles averaging 25 months was in November 1927, 203 months after the end of the three previous short cycles.

Following 1927, three more cycles ended in April 1938. These occupied 125 months, averaged $412 / 3$ months, and were completed 200 months after the three previous long cycles.

In summary, the 412 months following December 1903 contained three cycles averaging 28 months, then three averaging $422 / 3$, next three averaging 25 months, and finally three of $412 / 3$ average. Twenty six months, it will be noted, is one-eighth and $412 / 3$ is one fifth of 208 months. The period of 84 months is also approximately two periods of $412 / 3$ months.

In the 208 months since 1938, this pattern was interrupted by World War II and by ceiling prices after the peak of the first cycle. It appeared to resume at the end of the war and was again interrupted by the Korean conflict, ceilings, and armistice.

\section{Scrap Price Cycles and Others}

It would scarcely be supposed that scrap price cycles are an isolated phenomenon; they are not. Rate of change cycles occur in business activity and in the price of practically every unadministered commodity.

The Institute for Trend Research maintains a cyclical barometer which is a measure of the central tendency of rate of change in 15 different volume and dollar measurement series. In 5 out of 11 comparable cycles, the pressure rise in scrap steel has started at the same time as or one month sooner or later than a rise in the barometer. The relation at the cyclical high is not as close.

In a majority of 13 comparable cycles, the upturn in scrap price (1/12 Phase A) began from 7 months earlier to one month later than that of steel operations.

In minor cycles measured in weeks, cycles in steel scrap price usually correspond to cycles in the average price of metals.

\section{Summary}

1) For over 50 years scrap steel price has risen and fallen cyclically.

2) Its cyclical movement is compound of cycles which can be measured in years, others which are best measured in months, and some which must be measured in weeks.

3) Cycles can be effectively measured in terms of rate of change.

4) There appear to be definite laws governing cyclical change.

5) There is evidence of periodic tendencies in rate-of-change cycles.

6) Cycles in scrap price are related to cycles in other prices and in activity.

\section{References}

1 Paul T. Davis: A Description of the Hoskins Time Chart, Journal of Cycle Research, Vol. 5, No. 1, Jan., 1956. 